\title{
Arteriovenous extracorporeal lung assist allows for maximization of oscillatory frequencies: a large-animal model of respiratory
} distress

\author{
Ralf M Muellenbach*, Julian Kuestermann, Markus Kredel, Amélie Johannes, \\ Ulrike Wolfsteiner, Frank Schuster, Christian Wunder, Peter Kranke, \\ Norbert Roewer and Jörg Brederlau
}

\begin{abstract}
Address: University of Wuerzburg, Department of Anaesthesiology; University hospital Wuerzburg; Oberduerrbacherstr. 6; 97080 Wuerzburg, Germany

Email: Ralf M Muellenbach* - muellenbac_r@klinik.uni-wuerzburg.de; Julian Kuestermann - kuesterman_j@klinik.uni-wuerzburg.de; Markus Kredel - kredel_m@klinik.uni-wuerzburg.de; Amélie Johannes - johannes_a@klinik.uni-wuerzburg.de;

Ulrike Wolfsteiner - rmmuellenbach@gmx.de; Frank Schuster - schuster_f@klinik.uni-wuerzburg.de; Christian Wunder - wunder_c@klinik.uniwuerzburg.de; Peter Kranke - kranke_p@klinik.uni-wuerzburg.de; Norbert Roewer - roewer_n@klinik.uni-wuerzburg.de;

Jörg Brederlau - brederlau_j@klinik.uni-wuerzburg.de

* Corresponding author
\end{abstract}

Published: 14 November 2008

BMC Anesthesiology 2008, 8:7 doi:10.1 I86/147|-2253-8-7

This article is available from: http://www.biomedcentral.com/I47/-2253/8/7

(c) 2008 Muellenbach et al; licensee BioMed Central Ltd.

This is an Open Access article distributed under the terms of the Creative Commons Attribution License (http://creativecommons.org/licenses/by/2.0), which permits unrestricted use, distribution, and reproduction in any medium, provided the original work is properly cited.
Received: 21 March 2008

Accepted: 14 November 2008

\begin{abstract}
Background: Although the minimization of the applied tidal volume (VT) during high-frequency oscillatory ventilation (HFOV) reduces the risk of alveolar shear stress, it can also result in insufficient $\mathrm{CO}_{2}$-elimination with severe respiratory acidosis. We hypothesized that in a model of acute respiratory distress (ARDS) the application of high oscillatory frequencies requires the combination of HFOV with arteriovenous extracorporeal lung assist (av-ECLA) in order to maintain or reestablish normocapnia.
\end{abstract}

Methods: After induction of ARDS in eight female pigs ( $56.5 \pm 4.4 \mathrm{~kg}$ ), a recruitment manoeuvre was performed and intratracheal mean airway pressure (mPaw) was adjusted $3 \mathrm{cmH}_{2} \mathrm{O}$ above the lower inflection point (Plow) of the pressure-volume curve. All animals were ventilated with oscillatory frequencies ranging from $3-15 \mathrm{~Hz}$. The pressure amplitude was fixed at $60 \mathrm{cmH}_{2} \mathrm{O}$. At each frequency gas exchange and hemodynamic measurements were obtained with a clamped and de-clamped av-ECLA. Whenever the av-ECLA was de-clamped, the oxygen sweep gas flow through the membrane lung was adjusted aiming at normocapnia.

Results: Lung recruitment and adjustment of the mPaw above Plow resulted in a significant improvement of oxygenation $(\mathrm{P}<0.05)$. Compared to lung injury, oxygenation remained significantly improved with rising frequencies $(p<0.05)$. Normocapnia during HFOV was only maintained with the addition of av-ECLA during frequencies of $9 \mathrm{~Hz}$ and above.

Conclusion: In this animal model of ARDS, maximization of oscillatory frequencies with subsequent minimization of VT leads to hypercapnia that can only be reversed by adding av-ECLA. When combined with a recruitment strategy, these high frequencies do not impair oxygenation 


\section{Background}

The current strategy for conventional mechanical ventilation (CMV) in patients with acute respiratory distress syndrome (ARDS) is to prevent further lung injury which is a result of alveolar over-distension and the repetitive collapse and reopening of damaged alveoli [1-3]. Lung-protective ventilation using low tidal volume (VT) has been shown to reduce ventilator-induced lung injury (VILI) and mortality in patients with ARDS [2,4,5]. Theoretically high-frequency oscillatory ventilation (HFOV) achieves all goals of a lung-protective ventilatory mode. It provides the application of extremely small VTs combined with a relatively high mean airway pressure (mPaw). Thereby a more uniform lung recruitment can be achieved while the risk of tidal overdistension is minimized [6,7]. In adults with ARDS, HFOV can be safely applied and may improve gas exchange compared with CMV [8]. During HFOV, VT and thus carbon dioxide $\left(\mathrm{CO}_{2}\right)$-elimination are directly related to the applied pressure amplitude $(\Delta \mathrm{P})$ and the inspiratory/expiratory ratio and are inversely related to the oscillatory frequency- in other words: The lower the oscillatory frequency, the higher the resulting VT [9].

In adult HFOV trials the applied frequencies varied from 3-6 Hz and, in an attempt to maximize $\mathrm{CO}_{2}$-elimination, a $\Delta \mathrm{P}$ from $60-90 \mathrm{cmH}_{2} \mathrm{O}$ was used $[10,11]$. In these settings the resulting VTs resemble those during conventional lung-protective ventilation, thereby antagonizing the potential advantages of HFOV $[9,12]$. Although it was shown that higher oscillatory frequencies $(15 \mathrm{~Hz})$ might result in less neutrophil infiltration compared with lower frequencies $(5 \mathrm{~Hz})$ in a small animal model of respiratory distress, in adults the application of higher frequencies may lead to insufficient $\mathrm{CO}_{2}$-elimination with severe respiratory acidosis [13-15].

Recently, a new pumpless arteriovenous extracorporeal lung assist system (av-ECLA) has been introduced into clinical practice. It consists of a low-resistance membrane lung (iLA, NovaLung ${ }^{\circledast}$, Hechingen, Germany) interposed into a simple arteriovenous shunt between the femoral artery and vein [16]. Depending on the diameter of the cannulas, the cardiac output (CO) and the mean arterial pressure (MAP), the transmembraneous blood flow equals $20-30 \%$ of the CO [17]. With these flow rates near total extracorporeal $\mathrm{CO}_{2}$-removal could be achieved in animal models of respiratory failure, thereby allowing a more lung protective conventional ventilation strategy $[18,19]$.

While significant reductions in minute ventilation and VTs can be obtained during the combination of av-ECLA and conventional mechanical ventilation, optimal oscillatory frequencies remain to be determined. The current study was performed to evaluate the effects of different oscillatory frequencies on $\mathrm{CO}_{2}$-elimination with and without av-ECLA in a large-animal model of ARDS. We hypothesized that the application of high oscillatory frequencies, and thereby minimization of VT and alveolar stretch, requires the combination of HFOV with av-ECLA in order to maintain or re-establish normocapnia.

\section{Methods \\ Animal Preparation}

The study was conducted in accordance with the National Institutes of Health guidelines for ethical animal research and was approved by the Laboratory Animal Care and Use Committee of the District of Unterfranken, Germany. The experiments were performed on eight healthy female pigs $(56.5 \pm 4.4 \mathrm{~kg})$. Anaesthesia and instrumentation were carried out as previously described [20].

Shortly after intramuscular premedication with ketamin (10 mg/kg, ) an intravenous line was obtained and the animals were anaesthesized with continuous infusion of 5$10 \mathrm{mg} / \mathrm{kg}$ thiopental and $0.01 \mathrm{mg} / \mathrm{kg} / \mathrm{h}$ fentanyl throughout the experiment. Neuromuscular block was achieved by continuous infusion of $0.1 \mathrm{mg} / \mathrm{kg} / \mathrm{h}$ pancuronium.

The trachea was intubated with a cuffed $8.5 \mathrm{~mm}$ ID endotracheal tube with an additional side lumen ending at the tip (Rueschelit ${ }^{\circledR}$, Ruesch, Kernen, Germany). The lung was mechanically ventilated in the pressure controlled ventilation mode (EvitaXL, Dräger Medical, Lübeck, Germany) starting with a PEEP of $5 \mathrm{cmH}_{2} \mathrm{O}$, a VT of $6 \mathrm{ml} /$ $\mathrm{kg}$, a respiratory rate (RR) of $30 / \mathrm{min}$ and an inspiratory to expiratory ratio (I:E) of $1: 1$. The inspiratory oxygen fraction $\left(\mathrm{FiO}_{2}\right)$ remained 1.0 throughout the entire experiment. The core temperature was maintained at $38.0 \pm$ $0.5^{\circ} \mathrm{C}$ during the experiment by using a heating pad.

The animals were instrumented with a central venous line (Arrow International, Reading, PA, USA), an arterial catheter (Vygon, Ecouen, France) and a pulmonary artery catheter (831F75, Edwards Lifescience, Irvine, CA, USA). The position of the pulmonary artery catheter was verified by typical waveforms. After systemic heparinization (400 U/ $\mathrm{kg}$, Liquemin, Roche, Reinach, Switzerland) a 17 -French cannula was inserted into the right femoral artery and a 17-French cannula (NovaLung ${ }^{\circledR}$, Hechingen, Germany) into the left femoral vein using Seldinger technique and ultrasound guidance (SonoSite 180 Plus, SonoSite Inc., Botell, WA). A low-resistance pumpless extracorporeal lung assist device (iLA, NovaLung ${ }^{\circledR}$, Hechingen, Germany) was primed with heparinized isotonic saline $(150 \mathrm{ml})$ and connected to the femoral cannulas. The av-ECLA circuit was afterwards occluded with tubing clamps. The activated clotting time (ACT II, Medtronic, Minneapolis, MN) was measured hourly and maintained between 300-400 
seconds with continuous heparin infusion (1000 - 2000 $\mathrm{U} / \mathrm{h})$.

\section{Experimental Protocol}

The study protocol of the experiment is outlined in Fig. 1. After instrumentation, the animals were stabilized for 30 min and baseline measurements $\left(\mathrm{T}_{\text {Baseline }}\right)$ were obtained. Severe ARDS ( $\mathrm{T}_{\mathrm{ARDS}}$ ) was induced by bilateral pulmonary lavages with $30 \mathrm{ml} / \mathrm{kg}$ isotonic saline $\left(38^{\circ} \mathrm{C}\right)$, repeated every 10 minutes until $\mathrm{PaO}_{2}$ decreased to less than 60 $\mathrm{mmHg}$ and remained stable for 60 minutes with unchanged ventilator settings. An average of $7 \pm 2$ lavages with approximately $12.000 \mathrm{ml}$ saline per animal was necessary for ARDS induction. During induction all animals were ventilated with PCV $\left(\mathrm{FiO}_{2}=1.0, \mathrm{PEEP}=5 \mathrm{cmH}_{2} \mathrm{O}\right.$, $\mathrm{VT}=6 \mathrm{ml} / \mathrm{kg}, \mathrm{RR}=30 / \mathrm{min}, \mathrm{I}: \mathrm{E}=1: 1)$. After the induction of ARDS the lower inflection point (Plow) of the thoracic pressure-volume curve (PV) was determined in each animal. Accordingly, the animals were switched from PCV to HFOV (Sensor Medics 3100 B, Yorba Linda, CA, USA) and a lung recruitment manoeuvre (RM) was performed. This was realized by increasing the mean airway pressure (mPaw) to $50 \mathrm{cmH}_{2} \mathrm{O}$ without oscillations for $40 \mathrm{~s}$. The intratracheal mPaw was then adjusted $3 \mathrm{cmH}_{2} \mathrm{O}$ above Plow. Afterwards, HFOV was started with an oscillatory frequency of $3 \mathrm{~Hz}$ and RM measurements were obtained $\left(\mathrm{T}_{\mathrm{RM}}\right)$. Subsequently, the animals were ventilated with oscillatory frequencies ranging from $3 \mathrm{~Hz}$ to $15 \mathrm{~Hz}$. The frequency was altered in steps of $3 \mathrm{~Hz}$ in an incremental or decremental order. The starting oscillatory frequency was randomly assigned ( $3 \mathrm{~Hz}$ or $15 \mathrm{~Hz}$ to each half of the animals) to rule out a time effect in gas exchange and hemodynamic measurements due to recovery of the injured lung. At each oscillatory frequency, measurements were obtained with the av-ECLA circuit opened and closed. A 30-minute period was given for equilibration between each modification prior to data collection. The total study period lasted approximately 6 hours. As the avECLA circuit was de-clamped, normocapnia was attempted by adjusting the sweep gas flow through the membrane lung ( 0 - 10 l oxygen/min), which was applied via a calibrated $\mathrm{O}_{2}$-flowmeter (Draeger, Luebeck, Germany). Ventilator settings during HFOV were set as follows throughout the trial: $\mathrm{FiO}_{2}=1.0$, bias flow $=30 \mathrm{l} / \mathrm{min}$, oscillatory pressure amplitude $=60 \mathrm{cmH}_{2} \mathrm{O}, \mathrm{I}: \mathrm{E}=1: 1$. At the end of the study the oscillatory frequency was set at 3 $\mathrm{Hz}$ with the av-ECLA circuit clamped. A continuous colloid infusion (Voluven ${ }^{\circledR}$ 6\% HES 130/0.4, Fresenius Kabi, Bad Homburg, Germany) was administered in addition to a balanced electrolyte solution to maintain a mean arterial pressure $(\mathrm{MAP})>70 \mathrm{mmHg}$, which is mandatory to maintain sufficient blood flow through the membrane lung. Before killing the animals with an overdose of thiopental and embutramid mebezonium iodide ( $\mathrm{T} 61^{\circledR}$,
Intervet, Unterschleissheim, Germany) the PV curve was repeatedly measured.

\section{Measurements}

All measurements were performed during HFOV at different oscillatory frequencies $(3,6,9,12$ or $15 \mathrm{~Hz})$ with the av-ECLA circuit opened or closed (Fig. 1). For hemodynamic monitoring pressure transducers referenced to atmospheric pressure at the mid-thoracic level (Combitrans ${ }^{\circledR}$, Braun, Melsungen, Germany) and a modular monitor system (Servomed ${ }^{\circledR}$, Hellige, Freiburg i. Br., Germany) were used. MAP, mean pulmonary artery pressure (MPAP), central venous pressure (CVP) and pulmonary artery occlusion pressure (PCWP) were transduced. The heart rate (HR) was traced by the electrocardiogram. Threefold injections of 10-ml aliquots of ice cold saline into the right atrium were used for pulmonary artery catheter-based cardiac output measurements (Explorer $^{\circledR}$, Edwards Lifescience, Irvine, CA, USA).

Blood flow through the extracorporeal circuit was measured continuously with an ultrasonic flow probe (HT $110^{\circledR}$, Transonic, Ithaca, NY, USA). Arterial, post av-ECLA and mixed venous blood samples were immediately analyzed for $\mathrm{PO}_{2}, \mathrm{PCO}_{2}$ and $\mathrm{pH}$ using standard blood gas electrodes (ABL 505 ${ }^{\circledR}$, Radiometer, Bronshoj, Denmark). In each sample, hemoglobin and oxygen saturation were measured using spectrophotometry (OSM $3^{\circledR}$, Radiometer, Bronshoj, Denmark). Arterial and mixed venous oxygen contents $(\mathrm{ml} / \mathrm{dl})$ and the pulmonary shunt fraction (Qs/ $\mathrm{Qt})$ were calculated using standard formulas.

Intratracheal mean airway pressure (mPaw) was measured at the tubes tip using an air filled pressure transducer referenced to atmospheric pressure $\left(\mathrm{PM} 8050^{\circledR}\right.$, Draeger, Luebeck, Germany). Quasistatic pressure-volume curves of the respiratory system were obtained using the in- and expiratory low-flow pressure-volume manoeuvre of the Evita $\mathrm{XL}^{\oplus}$ ventilator. The start pressure was set at $0 \mathrm{cmH}_{2} \mathrm{O}$ and the peak inspiratory pressure at $50 \mathrm{cmH}_{2} \mathrm{O}$ with a flow rate of $4 \mathrm{l} / \mathrm{min}$ and a maximum volume of $2 \mathrm{l}$.

\section{Statistical analysis}

In each animal, both the starting oscillatory frequency (3 $\mathrm{Hz}$ or $15 \mathrm{~Hz}$ in each half of the animals; variation of frequency in steps of $3 \mathrm{~Hz}$ every $30 \mathrm{~min}$ ) and the order of opening and closing the av-ECLA at each frequency were randomized. The data of the incremental and decremental oscillatory trial were pooled and analyzed using SigmaStat 2.03 (Systat Software Inc., Point Richmond, USA). The data were tested for normal distribution using the Kolmogorov-Smirnov test. Values are reported as mean \pm SD. One and two-way analysis of variance (ANOVA) for repeated measurements were used for data analysis. Student-Newman-Keuls post hoc test was used for compari- 


$\sqrt{\text { Pressure Controlled Ventilation }(\mathrm{PCV})\left(\mathrm{T}_{\text {Baseline }}\right)}$

\begin{tabular}{|c|c|}
\hline 象 & $\begin{array}{l}\text { Acute Respiratory Distress Syndrome }\left(\mathrm{T}_{\text {ARDs }}\right) \\
\text { Repeated saline lavage }(7 \pm 2) \text { until } \mathrm{PaO}_{2} / \mathrm{FiO}_{2}<60 \mathrm{mmHg}\end{array}$ \\
\hline 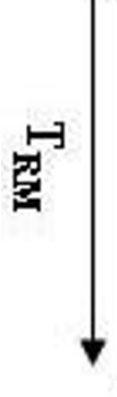 & $\begin{array}{c}\text { Recruitment Maneuver }\left(\mathrm{T}_{\mathrm{RM}}\right) \\
\text { - Intratracheal } \mathrm{mPaw} 50 \mathrm{cmH}_{2} \mathrm{O} \text { for } 40 \mathrm{~s} \text { without oscillation and } \\
\text { adjusting } \mathrm{mPaw} 3 \mathrm{cmH}_{2} \mathrm{O}>\mathrm{Plow} \\
\text { - HFOV: } \mathrm{FiO}_{2}=1.0, \text { Freq. }=3 \mathrm{~Hz}, \mathrm{I}: \mathrm{E}=1: 1, \\
\mathrm{Ampl}=60 \mathrm{cmH}_{2} \mathrm{O} \text {, av-ECLA off }\end{array}$ \\
\hline 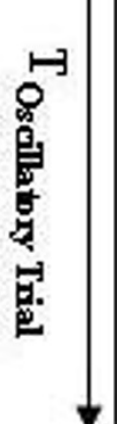 & $\begin{array}{c}\text { Oscillatory Frequency Trial } \\
- \text { Frequency steps from } 3 \text { to } 15 \mathrm{~Hz} \text { or } \\
15 \text { to } 3 \mathrm{~Hz}\left(\mathrm{FiO}_{2}=1.0, \mathrm{I}: \mathrm{E}=1: 1, \mathrm{Ampl}=60 \mathrm{cmH}_{2} \mathrm{O}\right) \\
\text { with the av-ECLA on and off (steps of } 3 \mathrm{~Hz} \text { ) } \\
-30 \text { min between each modification }\end{array}$ \\
\hline 我 & $\begin{array}{l}\text { End of Trial } \\
-\mathrm{HFOV}: \mathrm{FiO}_{2}=1.0 \text {, Freq. }=3 \mathrm{~Hz}, \mathrm{I}: \mathrm{E}=1: 1 \text {, } \\
\mathrm{Ampl}=60 \mathrm{cmH}_{2} \mathrm{O} \text {, av-ECLA off }\end{array}$ \\
\hline
\end{tabular}

Figure I

Study protocol and time course. $\mathrm{PCV}$, Pressure controlled ventilation; $\mathrm{HFOV}$, high-frequency oscillatory ventilation; $\mathrm{FiO}_{2}$, fraction of inspired oxygen; $P E E P$, positive endexpiratory pressure; $V T$, tidal volume; $R R$, respiratory rate; $I: E$, inspiratory:expiratory-ratio; $\mathrm{mPaw}$, mean pulmonary airway pressure; Plow, lower inflection point of the pressure-volume $\mathrm{curve}^{\mathrm{PaO}} \mathrm{O}_{2}$, arterial oxygen partial pressure; $\mathrm{PaCO}_{2}$, carbon dioxide partial pressure; av-ECLA, arteriovenous extracorporeal lung assist device. 
son of significant ANOVA results. Adjustment for multiple testing was performed. P values $<0.05$ were considered significant.

\section{Results}

All animals survived the complete study period. Gas exchange and hemodynamic parameters did not differ between the animals randomized for the incremental or decremental oscillatory trial before and after lung injury. After saline lavage, all animals developed severe respiratory failure (Table 1, Fig. 2, 3, and 4). Detailed data regarding gas exchange, respiratory parameters, hemodynamics and av-ECLA related parameters, are presented in Tables 1 and 2 .

\section{Pulmonary Gas Exchange}

Lung recruitment and adjusting the mPaw $3 \mathrm{cmH}_{2} \mathrm{O}$ above Plow during HFOV led to a significant improvement of $\mathrm{PaO}_{2}, \mathrm{SvO}_{2}$, and Qs/Qt-ratio (Table 1, Fig. 3, and $4, \mathrm{p}<0.05)$. At $\mathrm{T}_{\mathrm{RM}^{\prime}}$ at $3 \mathrm{~Hz} /$ ECLA and at $3 \mathrm{~Hz}, \mathrm{PaCO}_{2}$ was significantly reduced and $\mathrm{pH}$ was significantly increased compared with $\mathrm{T}_{\mathrm{ARDS}}$ (Table $1, \mathrm{p}<0.05$ ). $\mathrm{PaO}_{2}$ and Qs/Qtratio remained significantly improved with rising oscillatory frequencies compared with $\mathrm{T}_{\text {ARDS }}$ (Table 1 and Fig. 4, $\mathrm{p}<0.05)$. Pulmonary shunt fraction was significantly higher between $6 \mathrm{~Hz}$ and $12 \mathrm{~Hz}$ during HFOV compared with HFOV/av-ECLA (Table $1, \mathrm{p}<0.05$ ). $\mathrm{PaCO}_{2}$ was significantly reduced and $\mathrm{pH}$ was significantly higher between $6 \mathrm{~Hz}$ and $15 \mathrm{~Hz}$ with the av-ECLA opened as compared with HFOV alone (Table 1 and Fig. 2, p < 0.05). $\mathrm{SvO}_{2}$ was significantly higher during $\mathrm{HFOV} / \mathrm{av}-\mathrm{ECLA}$ compared with HFOV with all oscillatory frequencies

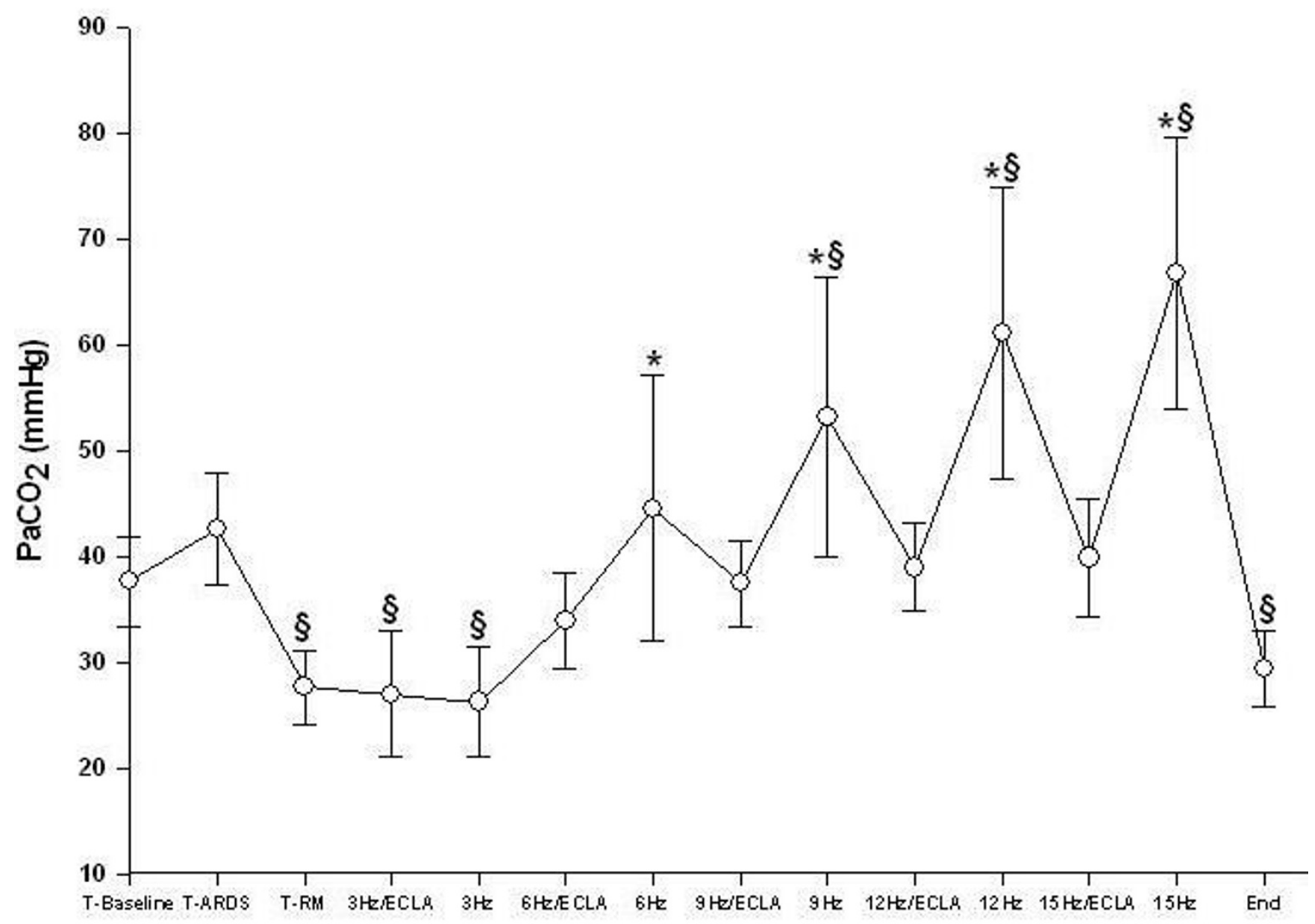

Figure 2

Arterial carbon dioxide partial pressure $\left(\mathrm{PaCO}_{2}\right)$ during different oscillatory frequencies with the arteriovenous extracorporeal lung assist device (ECLA) opened and closed. After recruitment and switching ventilation to HFOV the $\mathrm{PaCO}_{2}$ was significantly lower compared with lung injury $\left(\mathrm{T}_{\text {ARDS }}\right)(\S \mathrm{P}<0.05)$. The $\mathrm{PaCO} \mathrm{C}_{2}$ were significantly reduced from 6 to $15 \mathrm{~Hz}$ with the ECLA opened (*p $<0.05)$. 


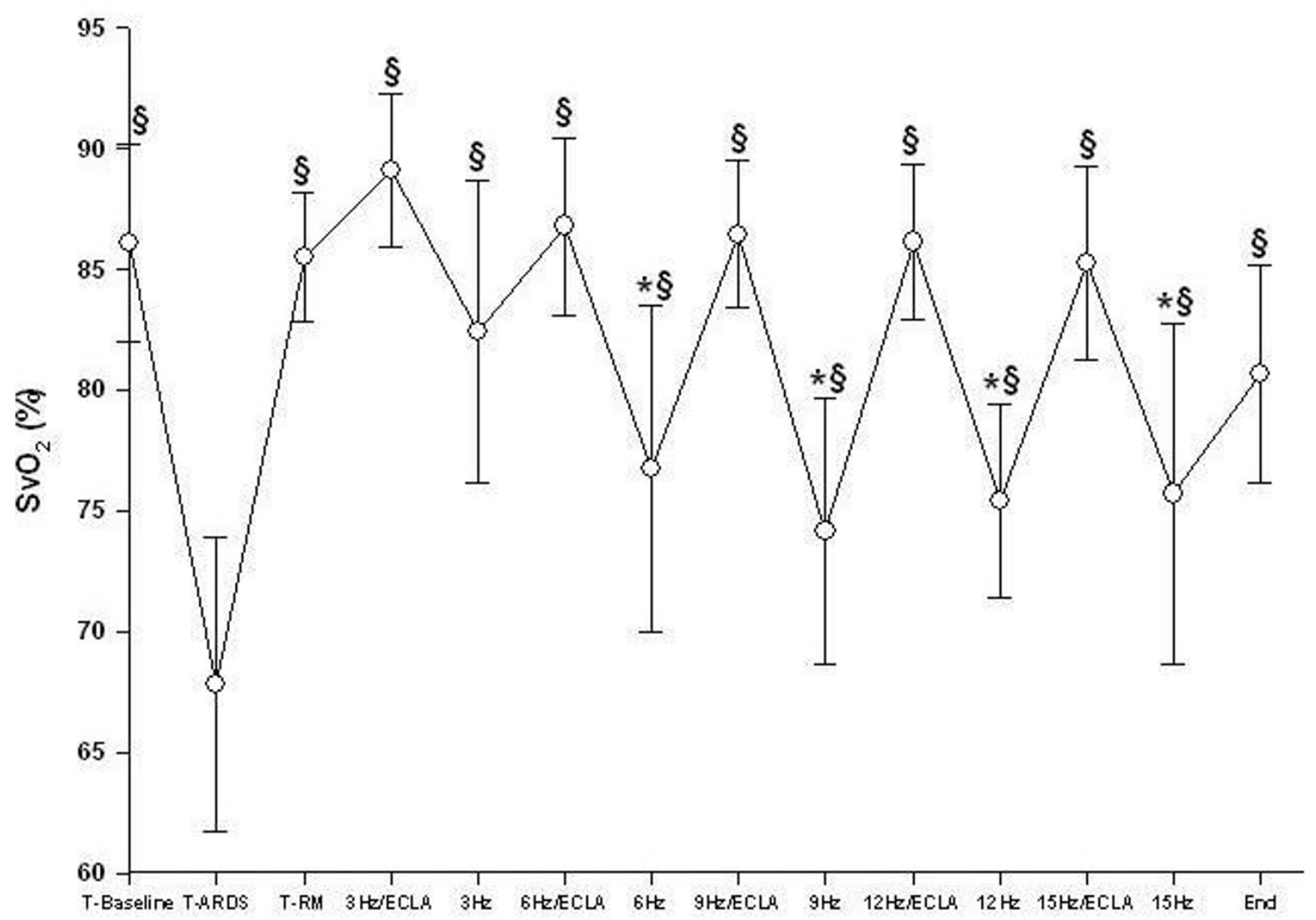

Figure 3

Mixed venous oxygen saturation $\left(\mathrm{SvO}_{2}\right)$ during different oscillatory frequencies with the arteriovenous extracorporeal lung assist device (ECLA) opened and closed. After recruitment and switching ventilation to $\mathrm{HFOV}_{\mathrm{H}}$ the $\mathrm{SvO}_{2}$ was significantly improved compared with lung injury $\left(\mathrm{T}_{\mathrm{ARDS}}\right)(\mathrm{SP}<0.05)$. The $\mathrm{SvO}_{2}$ were significantly increased from 6 to I $5 \mathrm{~Hz}$ with the ECLA device opened $(* p<0.05)$.

applied (Fig. 3, p < 0.05). At the end of the study, gas exchange parameters were not significantly different from $\mathrm{T}_{\mathrm{RM}}$ (Table 1).

\section{Hemodynamics and Oxygen Delivery}

After lung recruitment, CVP, MPAP, PCWP and $\mathrm{VO}_{2}$ were significantly elevated vs. $\mathrm{T}_{\text {ARDS }}$ (Table 1 and $2, \mathrm{p}<0.05$ ). CVP, MPAP and PCWP remained elevated compared with $\mathrm{T}_{\mathrm{ARDS}}$ throughout the study; significant differences between HFOV and HFOV/av-ECLA could be found in the PCWP at $9 \mathrm{~Hz}$ and $15 \mathrm{~Hz}$ (Table 2, p < 0.05). Heart rate and mean arterial pressure did not change significantly compared with $\mathrm{T}_{\mathrm{ARDS}}$ at different oscillatory frequencies. At $3 \mathrm{~Hz}$ and $9 \mathrm{~Hz}$, the HR was significantly higher during HFOV/av-ECLA (Table 2, $\mathrm{p}<0.05$ ). MAP was significantly elevated during HFOV at $3 \mathrm{~Hz}$ and $6 \mathrm{~Hz}$. SVR was significantly decreased and $\mathrm{CO}$ and $\mathrm{DO}_{2}$ were significantly increased during HFOV/av-ECLA compared with HFOV from $3 \mathrm{~Hz}$ to $15 \mathrm{~Hz}$ (Table 1 and 2, p < 0.05). PVR was significantly higher during HFOV compared with HFOV/avECLA between $6 \mathrm{~Hz}$ and $15 \mathrm{~Hz}$ (Table 2, p < 0.05). $\mathrm{VO}_{2}$ did not differ between study groups (Table 1 ).

\section{Arteriovenous extracorporeal lung assist device}

Blood gas analysis directly behind the membrane lung resulted in an oxygen partial pressure from $564 \pm 36$ $\mathrm{mmHg}$ to $628 \pm 22 \mathrm{mmHg}$. After applying higher oscillatory frequencies, normocapnia was achieved by increasing the $\mathrm{O}_{2}$-sweep gas flow from $2.4 \pm 2.3 \mathrm{l} / \mathrm{min}$ to $5.0 \pm 4.1 \mathrm{l} /$ min. Av-ECLA-blood flow was constant with $1.4 \pm 0.2 \mathrm{l} /$ 


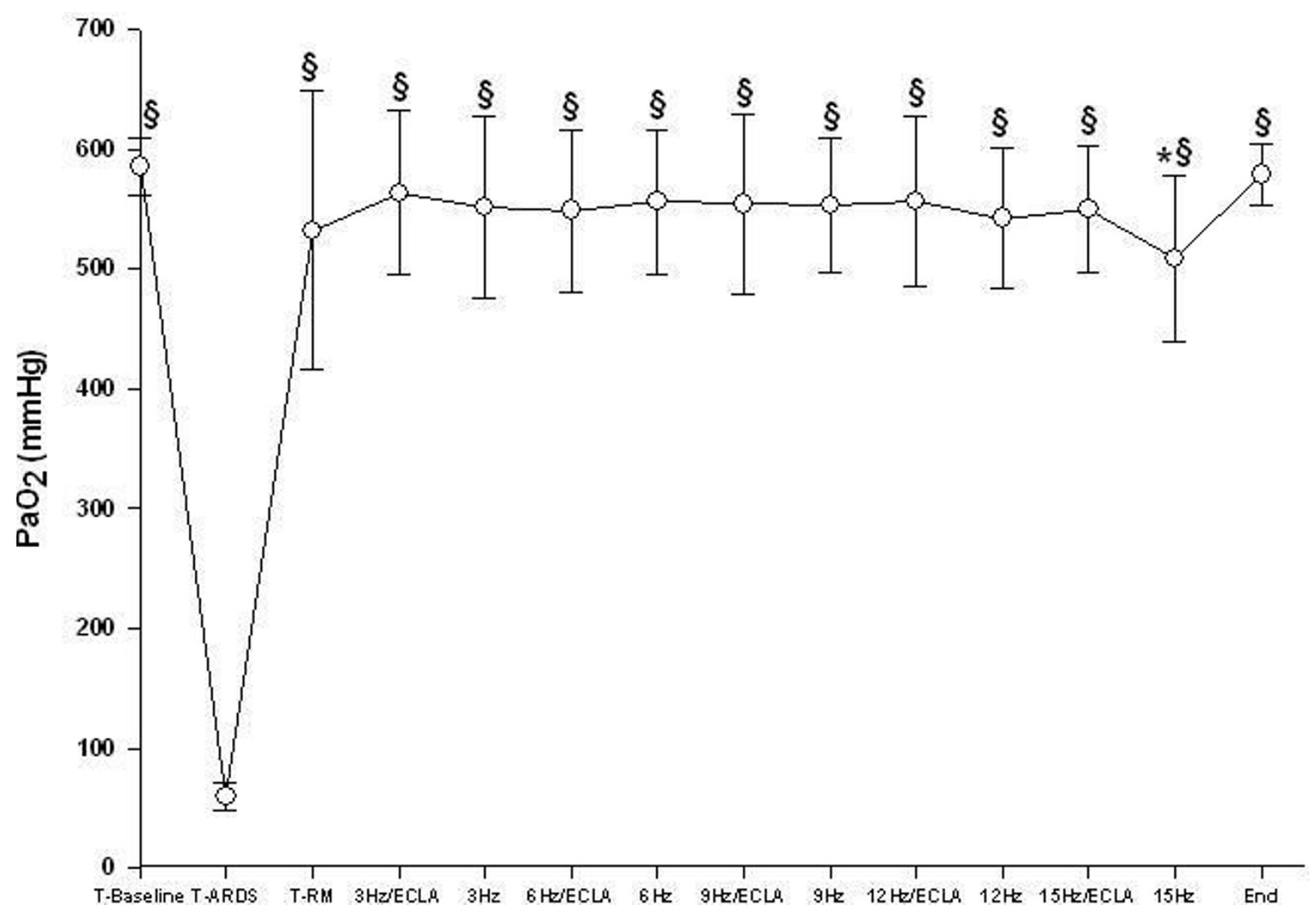

Figure 4

Arterial oxygen partial pressure $\left(\mathrm{PaO}_{2}\right)$ during different oscillatory frequencies with the arteriovenous extracorporeal lung assist device (ECLA) opened and closed. After lung recruitment and switching ventilation to HFOV the $\mathrm{PaO}_{2}$ was significantly higher compared with lung injury $\left(\mathrm{T}_{\mathrm{ARDS}}\right)(\S \mathrm{P}<0.05) . \mathrm{PaO}_{2}$ remained significantly improved with rising oscillatory frequencies compared with $\mathrm{T}_{\mathrm{ARDS}}(\$ \mathrm{P}<0.05)$. The $\mathrm{PaO}_{2}$ was significantly increased at $15 \mathrm{~Hz}$ with the ECLA opened $(* p<0.05)$.

min throughout the study, resulting in an av-ECLA-blood flow/CO-ratio of $21 \pm 6 \%$ to $27 \pm 6 \%$.

\section{Discussion}

The major findings of this study are twofold: (1) With oscillatory frequencies from 9-15 Hz normocapnia could only be maintained if HFOV was combined with av-ECLA. (2) After lung recruitment and setting the mPaw $3 \mathrm{cmH}_{2} \mathrm{O}$ above Plow, a sustained improvement in oxygenation was detectable even when oscillatory frequencies up to $15 \mathrm{~Hz}$ were used.

Conventional mechanical ventilation during severe ARDS can aggravate the progress of lung damage, especially when high tidal volumes are applied and repeated tidal collapse and reopening of damaged lung units occur. Limitation of the VT to $6 \mathrm{ml} / \mathrm{kg}$ of the predicted body weight, while keeping the lungs open with sufficient positive endexpiratory pressure (PEEP) can significantly reduce mortality in ARDS $[3,4]$. Further minimization of the VT combined with the application of high mean airway pressures may be achieved using HFOV [6]. Thereby, inspiratory overdistension and expiratory de-recruitment can be avoided [21]. Recently, it has been shown in a large-animal model of ARDS, that HFOV reduces histological signs of lung inflammation and messenger RNA expression of interleukin-1-beta in lung tissue compared to conventional lung-protective ventilation [22]. In most clinical studies using HFOV in adults, oscillatory frequencies between 3-6 Hz and pressure amplitudes between 60-90 $\mathrm{cmH}_{2} \mathrm{O}$ have been used $[10,11]$. If hypercapnia was evident during HFOV then oscillatory frequencies were decreased to $3 \mathrm{~Hz}$ and amplitudes were increased up to 90-100 $\mathrm{cmH}_{2} \mathrm{O}$. However, oscillatory frequencies below 
Table I: Gas exchange, respiratory and arteriovenous extracorporeal lung assist parameters, before and after lung injury, post recruitment and during the time course

\begin{tabular}{|c|c|c|c|c|c|c|c|}
\hline & $\mathbf{T}_{\text {Baseline }}$ & $\mathbf{T}_{\text {ARDS }}$ & $\mathbf{T}_{\mathrm{RM}}$ & $3 \mathrm{~Hz} / \mathrm{ECLA}$ & $3 \mathbf{H z}$ & $6 \mathrm{~Hz} / \mathrm{ECLA}$ & $6 \mathrm{~Hz}$ \\
\hline $\mathrm{RR}$ & $30+/-0$ & $30+/-0$ & $180+/-0 \S$ & $180+/-0 \S$ & $180+/-0 \S$ & $360+/-0 \oint$ & $360+/-0 \oint$ \\
\hline mPaw & $9.3+1-0.4 \S$ & $13.2+/-1.4$ & $22.6+/-1.1 \S$ & $22.6+/-1.1 \S$ & $22.6+/-1.1 \S$ & $22.6+/-1.1 \S$ & $22.6+/-1.1 \S$ \\
\hline $\mathrm{FiO}_{2}$ & $1.0+1-0$ & $1.0+/-0$ & $1.0+1-0$ & $1.0+1-0$ & $1.0+1-0$ & $1.0+1-0$ & $1.0+1-0$ \\
\hline $\mathrm{pHa}$ & $7.45+/-0.09$ & $7.41+/-0.06$ & $7.55+/-0.04 \S$ & $7.6+/-0.04 \S$ & $7.58+/-0.07 \S$ & $7.48+/-0.07$ & $7.4+/-0.08^{*}$ \\
\hline $\mathrm{PaO}_{2}$ & $585+/-24 \S$ & $60+/-12$ & $532+/-116 \S$ & $563+/-69 \S$ & $55 I+/-75 \S$ & $549+/-68 \S$ & $556+/-60 \S$ \\
\hline $\mathrm{PaCO}_{2}$ & $37.7+/-4.2$ & $42.7+/-5.3$ & $27.7+/-3.5 \S$ & $27.1+/-6 \S$ & $26.3+/-5.3 \S$ & $34+/-4.6$ & $44.6+/-12.5^{*}$ \\
\hline $\mathrm{SvO}_{2}$ & $86.1+/-4.1 \S$ & $67.9+/-6.1$ & $85.5+/-2.7 \S$ & $89.1+/-3.2 \S$ & $82.4+/-6.3 \S$ & $86.8+/-3.7 \S$ & $76.8+/-6.7 \S^{*}$ \\
\hline $\mathrm{DO}_{2}$ & $906+/-295$ & $739+/-251$ & $919+/-223$ & $920+/-198^{\circ}$ & $706+/-189 *$ & $804+/-192$ & $593+/-211^{*}$ \\
\hline $\mathrm{VO}_{2}$ & $197+/-35$ & $169+/-30$ & $214+/-34 \S$ & $|92+|-3 \mid$ & $|84+|-3 \mid$ & $182+/-39$ & $182+/-38$ \\
\hline $\mathrm{Qs} / \mathrm{Qt}$ & $0.07+/-0.02 \S$ & $0.54+/-0.09$ & $0.12+/-0.09 \S$ & $0.11+/-0.07 \S$ & $0.1+/-0.06 \S$ & $0.11+/-0.06 \S$ & $0.07+/-0.04 \S^{*}$ \\
\hline Plow & $5.8+/-0.5 \S$ & $19.6+1-1.1$ & & & & & \\
\hline $\mathrm{P}_{\mathrm{ECLA}} \mathrm{O}_{2}$ & & & & $564+/-36$ & & $574+/-45$ & \\
\hline SGF & & & & $0+/-0$ & & $2.4+/-2.3$ & \\
\hline EBF & & & & $1.4+/-0.2$ & & $1.4+/-0.2$ & \\
\hline \multirow[t]{2}{*}{$\mathrm{EBF} / \mathrm{CO}$} & & & & $21+/-6$ & & $25+/-6$ & \\
\hline & $9 \mathrm{~Hz} / \mathrm{ECLA}$ & $9 \mathrm{~Hz}$ & $12 \mathrm{~Hz} / \mathrm{ECLA}$ & $12 \mathrm{~Hz}$ & I $5 \mathrm{~Hz} / \mathrm{ECLA}$ & I $5 \mathrm{~Hz}$ & End \\
\hline $\mathrm{RR}$ & $540+/-0 \S$ & $540+/-0 \S$ & $720+/-0 \S$ & $720+/-0 \S$ & $900+1-0 \S$ & $900+/-0 \S$ & $180+/-0 \S$ \\
\hline mPaw & $22.6+/-1.1 \S$ & $22.6+/-1.1 \S$ & $22.6+/-1.1 \S$ & $22.6+/-1.1 \S$ & $22.6+/-I . I \S$ & $22.6+/-I .1 \S$ & $22.6+/-I .1 \S$ \\
\hline $\mathrm{FiO}_{2}$ & $1.0+1-0$ & $1.0+/-0$ & $1.0+1-0$ & $1.0+/-0$ & $1.0+1-0$ & $1.0+1-0$ & $1.0+1-0$ \\
\hline $\mathrm{pHa}$ & $7.46+/-0.05$ & $7.34+/-0.08^{*}$ & $7.45+/-0.05$ & $7.29+/-0.08 *$ & $7.43+/-0.06$ & $7.26+/-0.07^{*}$ & $7.54+/-0.05 \S$ \\
\hline $\mathrm{PaO}_{2}$ & $554+/-74 \S$ & $553+/-56 \S$ & $557+/-7 \mid \S$ & $542+/-59 \S$ & $550+/-53 \S$ & $508+/-70 \S S^{*}$ & $579+/-25 \S$ \\
\hline $\mathrm{PaCO}_{2}$ & $37.5+/-4$ & $53.2+/-13.3 \S *$ & $39+/-4.2^{\circ}$ & $61.1+/-13.7 \S^{*}$ & $39.9+/-5.5$ & $66.8+/-12.7 \S^{*}$ & $29.5+/-3.6 \S$ \\
\hline $\mathrm{SvO}_{2}$ & $86.5+/-3.1 \S$ & $74.2+/-5.5 \S^{*}$ & $86.1+/-3.2 \S$ & $75.5+/-4 \S^{*}$ & $85.3+/-4 \S$ & $75.7+/-7 \S^{*}$ & $80.7+/-4.5 \S$ \\
\hline $\mathrm{DO}_{2}$ & $764+/-152$ & $538+/-118^{*}$ & $767+/-110$ & $558+/-135^{*}$ & $819+/-194$ & $590+/-169 *$ & $616+/-76$ \\
\hline $\mathrm{VO}_{2}$ & $177+/-38$ & $|8|+/-32$ & $180+/-34$ & $|8|+/-36$ & $194+/-33$ & $182+/-29$ & $178+/-38$ \\
\hline Qs/Qt & $0.1+/-0.07 \S$ & $0.06+/-0.03 \S *$ & $0.1+/-0.07 \S$ & $0.06+/-0.04 \S^{*}$ & $0.1+/-0.05 \S$ & $0.08+1-0.04 \S$ & $0.08+/-0.03 \S$ \\
\hline Plow & & & & & & & $20.7+/-3.5$ \\
\hline $\mathrm{P}_{\mathrm{ECLA}} \mathrm{O}_{2}$ & $608+/-36$ & & $628+/-22$ & & $620+/-28$ & & \\
\hline SGF & $3.9+/-4.1$ & & $5+/-4$ & & $5+/-4.1$ & & \\
\hline EBF & $1.5+/-0.2$ & & $1.4+/-0.2$ & & $1.4+/-0.3$ & & \\
\hline $\mathrm{EBF} / \mathrm{CO}$ & $27+/-6$ & & $26+/-2$ & & $24+/-4$ & & \\
\hline
\end{tabular}

Data expressed as means \pm standard deviation; ECLA, arteriovenous extracorporeal lung assist; $A R D S$, acute respiratory distress syndrome; PRM, post recruitment; $R R$, respiratory rate per minute; $\mathrm{mPaw}$, mean pulmonary airway pressure in $\mathrm{cm} \mathrm{H}_{2} \mathrm{O} ; \mathrm{FiO}_{2}$, fraction of inspired oxygen; $\mathrm{PaO} \mathrm{O}_{2}$, arterial oxygen partial pressure in $\mathrm{mmHg} ; \mathrm{PaCO}_{2}$, arterial carbon dioxide partial pressure in $\mathrm{mmHg} ; \mathrm{SvO}_{2}$, mixed venous oxygen saturation; $\mathrm{DO}_{2}$, oxygen; delivery in I/min $/ \mathrm{m}^{2} ; \mathrm{VO}_{2}$, oxygen consumption in $\mathrm{I} / \mathrm{min} / \mathrm{m}^{2} ; \mathrm{Qs} / \mathrm{Qt}$, pulmonary shunt fraction; Plow, lower inflection point in $\mathrm{cmH}_{2} \mathrm{O} ; \mathrm{P}_{E C L A} \mathrm{O}_{2}$, partial oxygen pressure behind lung assist in mmHg; SGF, Sweep Gas Flow in 1/min; EBF, ECLA Blood Flow in 1/min; CO, cardiac output; * $p<0.05$ ECLA vs. No ECLA; $\$ p<0.05$ vs. $T_{\text {ARDs }}$.

$4 \mathrm{~Hz}$ combined with maximum pressure amplitudes resulted in tidal volumes comparable to conventional lung-protective ventilation, thereby antagonizing the potential advantages of HFOV [12].

The idea of decoupling ventilation and oxygenation was introduced by Gattinoni et al [23-25]: Extracorporeal $\mathrm{CO}_{2}$-elimination was provided by a veno-venous perfusion route with $20-30 \%$ of the cardiac output, whereas oxygenation was maintained by mechanical ventilation. Several animal and human trials showed the feasibility of reducing ventilator requirements during pump-driven extracorporeal $\mathrm{CO}_{2}$-removal $[23,24,26,27]$. However, despite technical advances of these systems, several sideeffects and complications impede its benefits, e.g., pump- induced traumatisation of blood cells, plasma leakage of oxygenator membranes and activation of the coagulation and inflammatory system.

Pumpless extracorporeal lung assist became feasible with the introduction of low-resistance membrane lungs that could be interposed into a simple arteriovenous shunt between the femoral artery and vein [28]. With the patient's heart as the driving force, the transmembranous blood flow is up to $25-30 \%$ of the CO, thereby allowing comparable $\mathrm{CO}_{2}$-elimination and reductions in ventilatory support achieved during pumpdriven extracorporeal $\mathrm{CO}_{2}$-removal [19]. In an adult sheep model of respiratory failure, av-ECLA allowed significant reductions in VTs (from $15 \pm 1.6$ to $3 \pm 1.5 \mathrm{ml} / \mathrm{kg}$ ), peak inspiratory pres- 
Table 2: Haemodynamic variables before and after lung injury, post recruitment and during the time course

\begin{tabular}{|c|c|c|c|c|c|c|c|}
\hline & $\mathbf{T}_{\text {Baseline }}$ & $\mathbf{T}_{\text {ARDS }}$ & $\mathbf{T}_{\mathrm{RM}}$ & $3 \mathrm{~Hz} / \mathrm{ECLA}$ & $3 \mathbf{H z}$ & $6 \mathrm{~Hz} / \mathrm{ECLA}$ & $6 \mathrm{~Hz}$ \\
\hline $\mathrm{HR} / \mathrm{min}$ & $72+/-18$ & $75+/-20$ & $78+/-24$ & $84+/-19$ & $75+/-18 *$ & $75+/-19$ & $7 \mid+/-17$ \\
\hline MAP & $66+1-3 \S$ & $81+/-8$ & $79+/-8$ & $74+/-9$ & $83+/-13^{*}$ & $78+/-9$ & $86+/-14^{*}$ \\
\hline CVP & $4.3+/-3.2$ & $4.8+/-2$ & $11.5+/-1.9 \S$ & $10.3+/-1.5 \S$ & $10.4+/-1.3 \S$ & $9.9+/-1.6 \S$ & $10.8+/-1.8 \S$ \\
\hline MPAP & $13+/-3,3$ & $15.6+/-2.1$ & $22.3+/-2.3 \S$ & $23.5+/-3.5 \S$ & $22.1+/-3.4 \S$ & $24.1+/-3 \S$ & $25+/-3.9 \S$ \\
\hline PCWP & $6.1+/-2$ & $7.3+/-2$ & $14.6+/-3.2 \S$ & $13.1+1-1.6 \S$ & $12.3+1-1.3 \S$ & $13.1+/-2 \S$ & $12.8+/-2.1 \S$ \\
\hline $\mathrm{CO}$ & $5.6+/-1.5$ & $6.8+/-2$ & $6.7+/-1.4 \#$ & $6.8+/-2$ & $5.3+/-1.8^{*}$ & $6+1-1.9$ & $4.4+/-2 \S *$ \\
\hline SVR & $926+/-264$ & $950+/-232$ & $845+/-228 \#$ & $801+/-253$ & $1220+/-449 *$ & $968+/-260$ & $|506+/-5| \mid \S^{*}$ \\
\hline \multirow[t]{2}{*}{ PVR } & $98+/-20$ & $106+/-29$ & $94+/-46 \#$ & $|34+|-6 \mid$ & $168+/-75$ & $159+/-66$ & $269+/-168 \oint^{*}$ \\
\hline & $9 \mathrm{~Hz} / \mathrm{ECLA}$ & $9 \mathrm{~Hz}$ & $12 \mathrm{~Hz} / \mathrm{ECLA}$ & $12 \mathrm{~Hz}$ & $15 \mathrm{~Hz} / \mathrm{ECLA}$ & $15 \mathrm{~Hz}$ & End \\
\hline $\mathrm{HR} / \mathrm{min}$ & $69+/-17$ & $60+/-15^{*}$ & $7 I+/-16$ & $62+/-14^{*}$ & $69+/-19$ & $63+/-21$ & $74+/-13$ \\
\hline MAP & $80+/-13$ & $84+/-14$ & $77+/-11$ & $80+/-13$ & $77+/-10$ & $75+/-15$ & $87+/-10$ \\
\hline CVP & $11+/-1.7 \S$ & $1 \mathrm{I}+/-2.3 \S$ & $10.9+/-1.6 \S$ & $10.6+1-1.2 \S$ & $11.3+1-1.6 \S$ & $10.1+1-1.8 \S$ & $10.4+/-1.4 \S$ \\
\hline MPAP & $25.1+/-1.8 \S$ & $25.3+/-3 \S$ & $23.8+1-1.9 \S$ & $25.1+/-3.5 \S$ & $23.3+/-3 \S$ & $25+/-3,9 \S$ & $23.5+/-3.6 \S$ \\
\hline PCWP & $13.9+/-1.5 \S$ & $12.3+/-1.3 \S^{*}$ & $13.3+1-1.3 \S$ & $12.8+1-1.8 \S$ & $14.6+1-2.1 \S$ & $13.3+/-1.3 \S^{*}$ & $12.6+1-0.9 \S$ \\
\hline $\mathrm{CO}$ & $5.7+/-1.5^{\circ}$ & $4+/-1 \S^{*}$ & $5.6+/-0.7$ & $4.1+/-0.9 \S^{*}$ & $6+/-1.1$ & $4.3+/-1.1 \S^{*}$ & $4.5+/-0.6 \S$ \\
\hline SVR & $1008+/-226$ & $1542+/-405 \S^{*}$ & $949+/-140$ & $1385+/-285 \S^{*}$ & $900+/-142$ & $1224+/-262^{*}$ & $1404+/-330 \S$ \\
\hline PVR & $|7|+/-54$ & $282+/-100 \S^{*}$ & $154+/-44$ & $242+/-58 \S^{*}$ & $119+/-38$ & $218+/-63 \S^{*}$ & $202+/-88 \S$ \\
\hline
\end{tabular}

Data expressed as means \pm standard deviation; $E C L A$, arteriovenous extracorporeal lung assist; $A R D S$, acute respiratory distress syndrome; PRM, post recruitment; $H R$, heart rate; $M A P$, mean arterial blood pressure in $\mathrm{mmHg} ; M P A P$, mean pulmonary artery pressure in mmHg; $P C W P$, pulmonary artery occlusion pressure in $\mathrm{mmHg} ; \mathrm{CO}$, cardiac output in I/min; SVR, systemic vascular resi stance in dyne $\cdot \mathrm{s} / \mathrm{cm}^{5} ; P V R$, pulmonary vascular resi stance in dyne.s/cm $5 * *<0.05$ ECLA vs. No ECLA; $\$ p<0.05$ vs. $\mathrm{T}_{\mathrm{ARDs}} ; \# p<0.05 \mathrm{~T}_{\mathrm{RM}}$ vs. End.

sures $\left(40 \pm 2.1\right.$ to $\left.20 \pm 7.5 \mathrm{cmH}_{2} \mathrm{O}\right)$ and minute ventilation $(10 \pm 1.4$ to $0.5 \pm 0 \mathrm{~L} / \mathrm{min})[19]$.

The goal of this large-animal study of ARDS was to evaluate the effects of HFOV during different oscillatory frequencies on $\mathrm{CO}_{2}$-elimination with and without the application of av-ECLA. Our results clearly demonstrate that normocapnia was not achieved and respiratory acidosis developed if higher oscillatory frequencies (>9 Hz) were used without av-ECLA. Although 'permissive hypercapnia' might be one element of a lung-protective ventilation strategy because of its potential beneficial effects, such as suppression of lung inflammation, the safe level of hypercapnia and the respiratory acidosis remains unknown [29]. In addition, there are clinical situations where hypercapnia is contraindicated, e.g. in patients with decreased cerebral compliance [30].

It has now been accepted, that VT-reduction is the key factor to improving outcome and to protecting the lungs from further damage, whereas the optimal VT remains unclear [4,31]. In our study, the implementation of avECLA allowed the use of maximal oscillatory frequencies (up to $15 \mathrm{~Hz}$ ), similar to those applied during neonatal HFOV, without the risk of hypercapnia or respiratory acidosis. Although not measured in this study, with the settings chosen, the resulting VTs can safely be assumed to be below $1 \mathrm{ml} / \mathrm{kg}$ of the predicted body weight [16,32]. Nevertheless, mere VT-reduction during conventional ventilation leads to low peak pressure ventilation favouring further lung de-recruitment [33]. Very recently, Dembinski and co-workers compared the use of av-ECLA and VTreduction to $3 \mathrm{ml} / \mathrm{kg}$ with a conventional low-tidal volume $(6 \mathrm{ml} / \mathrm{kg})$ ventilation strategy in a large-animal model of ARDS [34]. After 24 hours, the VT-reduction in the av-ECLA group resulted in a significant impairment of oxygenation and an increase of the pulmonary shunt fraction compared with the CMV group. However, the PEEP levels used in this study were very low and insufficient in preventing lung de-recruitment. In ARDS patients ventilated with low tidal volumes, de-recruitment is usually reversed by a recruitment manoeuvre or prevented by an adequate PEEP level [33]. Adjusting the mPaw level for optimal lung recruitment remains difficult during HFOV. Usually mPaw during $\mathrm{HFOV}$ is set 3 to $5 \mathrm{cmH}_{2} \mathrm{O}$ higher than the mPaw used during CMV [21]. In an animal model of respiratory distress, it was shown that setting the mPaw $6 \mathrm{cmH}_{2} \mathrm{O}$ above the lower inflection point of the pressure-volume curve yielded the best oxygenation [21]. Using a similar recruitment strategy, we found sustained improvements of oxygenation, even with maximum oscillatory frequencies. Since VT can be minimized when HFOV is combined with av-ECLA, an optimal recruitment of lung volume appears to be essential in this setting.

The study design implies the following limitations: First, we used an ARDS model based on surfactant-depletion. In adults, not surfactant deficiency, but alveolar flooding is the predominant mechanism in ARDS development with surfactant-depleted lungs responding better to lung 
recruitment [35]. Second, the Sensormedics 3100 B oscillator is a pressure cycling machine that can neither control nor directly measure VTs. Hence, in this study no direct statement regarding the applied VTs can be made. However, in a recent observational study VT was measured directly during HFOV in ARDS patients: It was shown, that the tidal volumes during HFOV with frequencies between 5 and $12 \mathrm{~Hz}$ are between 0.8 and $3.3 \mathrm{ml} / \mathrm{kg}$ of the predicted body weight [12]. Third, the study protocol did not allow alterations of the pressure amplitude and I:E-ratio in order to improve $\mathrm{CO}_{2}$-elimination. Both parameter settings refer to previous experimental large-animal studies of HFOV and clinical practice $[11,22,36]$. However, if maximal oscillatory frequencies without av-ECLA were used, only moderate hypercapnia and respiratory acidosis developed. Therefore, one might argue, that without avECLA $\mathrm{CO}_{2}$-elimination could have been improved by adjusting the pressure amplitude and I:E-ratio to 90-100 $\mathrm{cmH}_{2} \mathrm{O}$ and $1: 2$, respectively. On the other hand, with near total $\mathrm{CO}_{2}$-removal due to extracorporeal lung assist, the applied pressures and accordingly the applied VT could have been further reduced, thereby minimizing VT and alveolar shear stress. Finally, av-ECLA allows for decoupling of ventilation and oxygenation. Therefore, the application of more lung-protective ventilator settings is not only possible, but should also be examined. However, it was not the purpose of this study to examine the effect of higher frequency HFOV on lung damage.

Despite the potential benefits with regard to lung protective ventilation strategies, different complications are described during av-ECLA. These included infections, ischemia of the lower limb after cannulation, bleeding and cannula thrombosis [16]. In addition, the device should not be used in patients with cardiogenic shock, heparin-induced thrombocytopenia and severe peripheral arterial occlusive disease.

\section{Conclusion}

In conclusion, we demonstrate in a large-animal model of ARDS, that the combination of HFOV and av-ECLA guarantees normocapnia even with maximal oscillatory frequencies of 9 to $15 \mathrm{~Hz}$. In this context, av-ECLA can be interpreted as a tool to unmask the entire lung protective potential of HFOV. Minimization of the applied VT does not only limit tidal overdistension and volutrauma, but also facilitates lung recruitment and prevents the lungs from atelactrauma since the application of higher mean airway pressures is possible. Thereby, oxygenation can be maintained. Histologic and immunologic data are needed in order to prove the lung protective effects of the proposed therapeutic concept.

In a further trial, it should be evaluated whether the combination of HFOV with maximal oscillatory frequencies and the av-ECLA result in further lung-protection when compared to conventional lung-protective ventilation.

\section{Abbreviations}

ARDS: Acute respiratory distress syndrome; av-ECLA: Arteriovenous extracorporeal lung assist; $\mathrm{CMV}$ : Conventional mechanical ventilation; $\mathrm{CO}$ : Cardiac output; $\mathrm{CO}_{2}$ : carbon dioxide; CVP: Central venous pressure; $\mathrm{DO}_{2}$ : Oxygen delivery; $\mathrm{FiO}_{2}$ : Inspiratory oxygen fraction; HFOV: Highfrequency oscillatory ventilation; HR: Heart rate; I:E: Inspiratory to expiratory ratio; MAP: Mean arterial pressure; mPaw: Mean airway pressure; MPAP: Mean pulmonary artery pressure; $\mathrm{PaCO}_{2}$ : Arterial carbon dioxide tension; $\mathrm{PaO}_{2}$ : Arterial oxygen tension; PCWP: Pulmonary artery wedge pressure; PEEP: Positive end-expiratory pressure; PIP: Peak inspiratory pressure; Plow: Lower inflection point; PRM: Post recruitment measurements; PV: Pressure-volume curve; PVR: Pulmonary vascular resistence; Qs/Qt: pulmonary shunt fraction; RM: Recruitment manoeuvre; RR: Respiratory rate; $\mathrm{SvO}_{2}$ : Mixed venous oxygen tension; SVR: System vascular resistance; VILI: Ventilator-induced lung injury; $\mathrm{VO}_{2}$ : Oxygen consumption; VT: Tidal volume.

\section{Competing interests}

The authors declare that they have no competing interests.

\section{Authors' contributions}

RMM designed the study, collected data, and drafted the manuscript. JK collected the data and helped to write the manuscript. MK and AJ performed the statistical analysis. UW collected data. FS participated in the design of the study. CW, PK and NR helped to interpret the results and write the manuscript. JB drafted the manuscript and participated in the design of the study. All authors read and approved the final manuscript.

\section{Acknowledgements}

The authors thank Alois Reichert for his technical support, Brigitte Paul and Juergen Schoell for their logistic support and Karin Ulrichs, Ph.D. for her organisational support.

\section{References}

I. Tremblay LN, Miatto D, Hamid Q, Govindarajan A, Slutsky AS: Injurious ventilation induces widespread pulmonary epithelial expression of tumor necrosis factor-alpha and interleukin-6 messenger RNA. Crit Care Med 2002, 30:1693-1700.

2. Pinhu L, Whitehead T, Evans T, Griffiths M: Ventilator-associated lung injury. Lancet 2003, 36 I:332-340.

3. Amato MB, Barbas CS, Medeiros DM, Magaldi RB, Schettino GP, Lorenzi-Filho G, et al.: Effect of a protective-ventilation strategy on mortality in the acute respiratory distress syndrome. $\mathrm{N}$ Engl J Med 1998, 338:347-354.

4. Ventilation with lower tidal volumes as compared with traditional tidal volumes for acute lung injury and the acute respiratory distress syndrome. The Acute Respiratory Distress Syndrome Network. N Engl J Med 2000, 342: I30 I-I 308.

5. Ranieri VM, Giunta F, Suter PM, Slutsky AS: Mechanical ventilation as a mediator of multisystem organ failure in acute respiratory distress syndrome. JAMA 2000, 284:43-44. 
6. Ferguson ND, Villar J, Slutsky AS: Understanding high-frequency oscillation: lessons from the animal kingdom. Intensive Care Med 2007, 33:1316-1318.

7. Luecke T, Herrmann P, Kraincuk P, Pelosi P: Computed tomography scan assessment of lung volume and recruitment during high-frequency oscillatory ventilation. Crit Care Med 2005, 33:SI55-SI62.

8. Downar J, Mehta S: Bench-to-bedside review: high-frequency oscillatory ventilation in adults with acute respiratory distress syndrome. Crit Care 2006, 10:240.

9. Sedeek KA, Takeuchi M, Suchodolski K, Kacmarek RM: Determinants of tidal volume during high-frequency oscillation. Crit Care Med 2003, $31: 227-231$.

10. Fort P, Farmer C, Westerman J, Johannigman J, Beninati W, Dolan S, et al:: High-frequency oscillatory ventilation for adult respiratory distress syndrome-a pilot study. Crit Care Med 1997, 25:937-947.

II. Derdak S, Mehta S, Stewart TE, Smith T, Rogers M, Buchman TG, et al.: High-frequency oscillatory ventilation for acute respiratory distress syndrome in adults: a randomized, controlled trial. Am J Respir Crit Care Med 2002, 166:80I-808.

12. Hager DN, Fessler HE, Kaczka DW, Shanholtz CB, Fuld MK, Simon $\mathrm{BA}$, et al.: Tidal volume delivery during high-frequency oscillatory ventilation in adults with acute respiratory distress syndrome. Crit Care Med 2007, 35: 1522-1529.

13. Meyer J, Cox PN, McKerlie C, Bienzle D: Protective Strategies of High-frequency Oscillatory Ventilation in a Rabbit Model. Pediatr Res 2006.

14. David M, Heinrichs W: High-frequency oscillatory ventilation and an interventional lung assist device to treat hypoxaemia and hypercapnia. Br J Anaesth 2004, 93:582-586.

15. Froese $A B$ : The incremental application of lung-protective high-frequency oscillatory ventilation. Am J Respir Crit Care Med 2002, 166:786-787.

16. Bein T, Weber F, Philipp A, Prasser C, Pfeifer M, Schmid FX, et al.: A new pumpless extracorporeal interventional lung assist in critical hypoxemia/hypercapnia. Crit Care Med 2006, 34:1372-1377.

17. Brederlau J, Muellenbach R, Kredel M, Schwemmer U, Anetseder M, Greim $C$, et al:: The contribution of arterio-venous extracorporeal lung assist to gas exchange in a porcine model of lavage-induced acute lung injury. Perfusion 2006, $21: 277-284$

18. Brunston RL Jr, Tao W, Bidani A, Cardenas VJ Jr, Traber DL, Zwischenberger JB: Determination of low blood flow limits for arteriovenous carbon dioxide removal. ASAIO J 1996, 42:M845-M849.

19. Tao W, Brunston RL Jr, Bidani A, Pirtle P, Dy J, Cardenas VJ Jr, et al:: Significant reduction in minute ventilation and peak inspiratory pressures with arteriovenous $\mathrm{CO} 2$ removal during severe respiratory failure. Crit Care Med 1997, 25:689-695.

20. Muellenbach RM, Kredel M, Zollhoefer B, Wunder C, Roewer N, Brederlau J: Sustained inflation and incremental mean airway pressure trial during conventional and high-frequency oscillatory ventilation in a large porcine model of acute respiratory distress syndrome. BMC Anesthesiol 2006, 6:8.

21. Chan KP, Stewart TE, Mehta S: High-frequency oscillatory ventilation for adult patients with ARDS. Chest 2007, I31:1907-1916.

22. Muellenbach RM, Kredel M, Said HM, Klosterhalfen B, Zollhoefer B, Wunder $C$, et al.: High-frequency oscillatory ventilation reduces lung inflammation: a large-animal 24-h model of respiratory distress. Intensive Care Med 2007, 33:|423-|433.

23. Gattinoni L, Kolobow T, Tomlinson T, lapichino G, Samaja M, White $D$, et al.: Low-frequency positive pressure ventilation with extracorporeal carbon dioxide removal (LFPPV-ECCO2R): an experimental study. Anesth Analg 1978, 57:470-477.

24. Gattinoni L, Kolobow T, Tomlinson T, White D, Pierce J: Control of intermittent positive pressure breathing (IPPB) by extracorporeal removal of carbon dioxide. $\mathrm{Br} J$ Anaesth 1978, 50:753-758.

25. Kolobow T, Gattinoni L, Tomlinson T, Pierce JE: An alternative to breathing. J Thorac Cardiovasc Surg 1978, 75:26I-266.

26. Gattinoni L, Kolobow T, Agostoni A, Damia G, Pelizzola A, Rossi GP et al: Clinical application of low frequency positive pressure ventilation with extracorporeal CO2 removal (LFPPV-
ECCO2R) in treatment of adult respiratory distress syndrome (ARDS). Int J Artif Organs 1979, 2:282-283.

27. Gattinoni L, Agostoni A, Pesenti A, Pelizzola A, Rossi GP, Langer M, et al: Treatment of acute respiratory failure with low-frequency positive-pressure ventilation and extracorporeal removal of CO2. Lancet 1980, 2:292-294.

28. Grubitzsch H, Beholz S, Wollert HG, Eckel L: Pumpless arteriovenous extracorporeal lung assist: what is its role? Perfusion 2000, 15:237-242.

29. Sinclair SE, Kregenow DA, Lamm WJ, Starr IR, Chi EY, Hlastala MP: Hypercapnic acidosis is protective in an in vivo model of ventilator-induced lung injury. Am J Respir Crit Care Med 2002, 166:403-408.

30. Bein T, Scherer MN, Philipp A, Weber F, Woertgen C: Pumpless extracorporeal lung assist ( $\mathrm{EECLA}$ ) in patients with acute respiratory distress syndrome and severe brain injury. J Trauma 2005, 58: 1294-1297.

31. Ranieri VM, Suter PM, Tortorella C, De Tullio R, Dayer JM, Brienza $A$, et al: Effect of mechanical ventilation on inflammatory mediators in patients with acute respiratory distress syndrome: a randomized controlled trial. JAMA I999, 282:54-6I.

32. Fessler HE, Hess DR: Respiratory controversies in the critical care setting. Does high-frequency ventilation offer benefits over conventional ventilation in adult patients with acute respiratory distress syndrome? Respir Care 2007, 52:595-605.

33. Richard JC, Maggiore SM, Jonson B, Mancebo J, Lemaire F, Brochard $L$ : Influence of tidal volume on alveolar recruitment. Respective role of PEEP and a recruitment maneuver. Am J Respir Crit Care Med 200I, 163:1609-1613.

34. Dembinski R, Hochhausen N, Terbeck S, Uhlig S, Dassow C, Schnei$\operatorname{der} M$, et al.: Pumpless extracorporeal lung assist for protective mechanical ventilation in experimental lung injury. Crit Care Med 2007, 35:2359-2366.

35. Karmrodt J, Bletz C, Yuan S, David M, Heussel CP, Markstaller K Quantification of atelectatic lung volumes in two different porcine models of ARDS. Br J Anaesth 2006, 97:883-895.

36. Sedeek KA, Takeuchi M, Suchodolski K, Vargas SO, Shimaoka M, Schnitzer J], et al.: Open-lung protective ventilation with pressure control ventilation, high-frequency oscillation, and intratracheal pulmonary ventilation results in similar gas exchange, hemodynamics, and lung mechanics. Anesthesiology 2003, 99:।102-IIII.

\section{Pre-publication history}

The pre-publication history for this paper can be accessed here:

http://www.biomedcentral.com/1471-2253/8/7/prepub

Publish with Bio Med Central and every scientist can read your work free of charge

"BioMed Central will be the most significant development for disseminating the results of biomedical research in our lifetime."

Sir Paul Nurse, Cancer Research UK

Your research papers will be:

- available free of charge to the entire biomedical community

- peer reviewed and published immediately upon acceptance

- cited in PubMed and archived on PubMed Central

- yours - you keep the copyright
BiolMedcentral 